\title{
Improving Voltage Profile of Islanded Microgrid using PI Controller
}

\author{
Sajid Hussain Qazi ${ }^{1}$, M. W. Mustafa ${ }^{2}$ \\ ${ }^{1,2}$ Faculty of Electrical Engineering, Universiti Teknologi Malaysia, Malaysia \\ ${ }^{1}$ Departement of Electrical Engineering, Mehran UET SZAB Campus, Khairpur Mir's, Sindh, Pakistan
}

\begin{tabular}{l} 
Article Info \\
\hline Article history: \\
Received Jan 17, 2018 \\
Revised Mar 21, 2018 \\
Accepted Apr 4, 2018
\end{tabular}

Keyword:

Microgrid

PCC

PI controller

Voltage regulation

\begin{abstract}
In islanding operating mode of microgrid, the voltage and frequency of system must be maintained by the microgrid, or else the system will crumble due to the characteristics of different distributed generators (DG) utilized in microgrid. The voltage and frequency lost provision when main grid is disconnected. This paper presents PI controller based voltage controller to regulate voltage to its normal condition. The controller is proposed to be utilized individually with each distributed generator (DG) in microgrid. The controller compares inverter output voltage with voltage at point of common coupling (PCC) and its output is feed to PWM pulse generator to generate appropriate pulses for inverter to regulate voltage to its nominal value. The simulation results of proposed system are shown using MATLAB/Simulink platform.
\end{abstract}

Copyright () 2018 Institute of Advanced Engineering and Science. All rights reserved.

\section{Corresponding Author:}

Sajid Hussain Qazi

Departement of Electrical Engineering,

Mehran UET SZAB Campus,

Khairpur Mir's, 66020, Sindh, Pakistan.

Email: qazi.sajidhussain@yahoo.co.uk

\section{INTRODUCTION}

Keeping in view the protection of environmental, economic aspects, energy conservation, and technical challenges, the microgrid has developed as a pioneering power generation network on small scale ratings. The cluster of small distributed generator units (such as PV arrays, wind turbines, batteries, fuel cells, etc.), composes a microgrid, and incorporate sharing of distribution system of electrical power and may be dependent on different energy generating sources [1-3]. These DG's are commonly attached to the power system by mean of Pulse Width Modulation (PWM) based Voltage Source Inverter (VSI) [4], [5]. This have nonlinear V-I characteristics, and generate high switching frequency, both affect the quality of supplied power for the end user [6].

Furthermore, the operation of microgrid depends on three main factors. Firstly, the type of DG units employed; these can be classified as power sources. Secondly, the DC/AC PWM-VSI system; usually used as interfacing of DG units either to the utility grid or directly to load and affect the operation of microgrid through generation of harmonics, increasing system dynamics band, and limiting the overload proficiency of system. Third, the controller used for the DC/AC PWM-VSI; the operation of microgrid is mostly controlled by the VSI system, so for reliable operation of microgrid an effective control loop is compulsory [7], [8].

The quality of power primarily depends on the fault occurrence from short to long periods or variations in the characteristics of output power [9], [10]. The most serious problems of microgrid which affect power quality can be categorized by operating mode of microgrid [11]. In a microgrid (islanding) mode, the profile of voltage and frequency have to be maintained by the microgrid itself, if not the system will malfunction due to the nature of the attached DG units and the power converter [12]. An appropriate method for load sharing among the DG units must be selected for sharing the load [13], [14]. 
The problem of voltage during islanding operation of microgrid is similar to voltage drop deviations in emergency conditions by connecting DVR (Dynamic Voltage Restorer) which is custom power device in existing distribution system [15], [16]. But in case of microgrid, unlike DVR, it has no limitation of energy capacity on direct current side. So there is a need of many studies over improvement of voltage quality controlling micro sources, not custom power devices [17], [18].

Following this paper, we considered a distribution system connected with microgrid using MATLAB/Simulink. Dynamic behavior of microgrid DG units have been shown when suddenly microgrid is disconnected from main grid system due to some faults. The simulation results also giving performance of proposed controller in maintaining supply voltage and frequency to its normal value after the disturbance of grid.

\section{RESEARCH METHODOLOGY}

The proposed methodology considered in this study is discussed in following subsections.

\subsection{Proposed microgrid system}

Figure 1 showing the studied structure of microgrid connected with main grid. In addition, with the local loads, the proposed system contains Batteries, Solid Oxide Fuel Cells (SOFC), Asynchronous machine and PV array of different power ratings. In the proposed model, MG can be operated in grid connected mode or in islanding mode by changing states of three phase breaker or during faults at main grid. This research paper mainly controls the voltage when suddenly there occurs a fault on grid or grid disconnected from MG. In any case, the proposed controller will maintain the terminal voltage to its normal value to supply uninterrupted voltage to the loads. The rating of each DG and loads are given in Table 1 and Table 2.

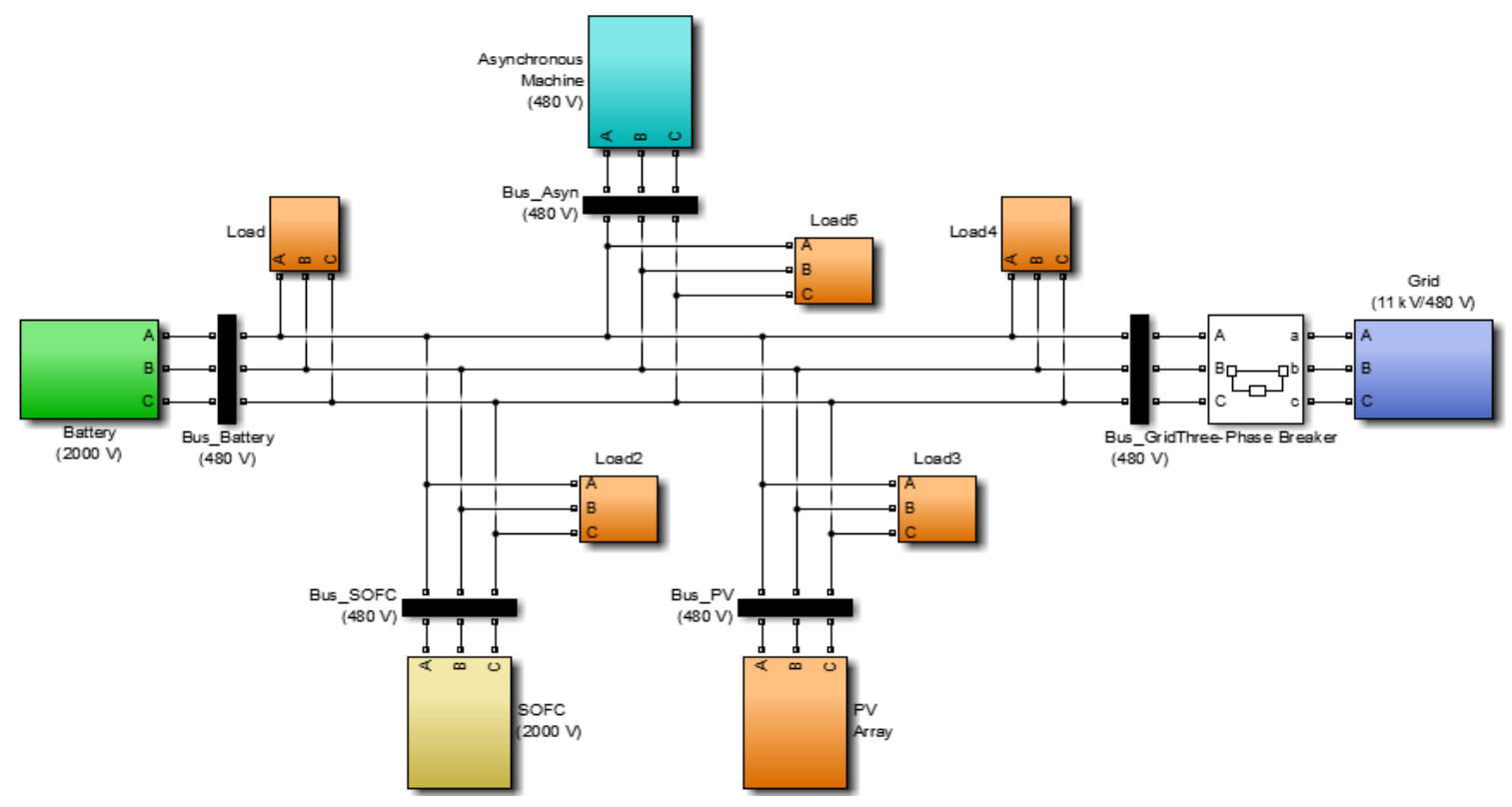

Figure 1. Proposed grid connected microgrid system

Table 1. Ratings of Distributed Generators

\begin{tabular}{cc}
\hline Type of DG & Rating \\
\hline Battery & $40 \mathrm{~kW}$ \\
SOFC & $30 \mathrm{~kW}$ \\
PV Array & $40 \mathrm{~kW}$ \\
Asynchronous Machine & $100 \mathrm{~kW}$ \\
\hline
\end{tabular}


Table 2. Load Ratings

\begin{tabular}{ll}
\hline Load 1 & $\mathrm{P}=100 \mathrm{~kW}, \mathrm{QL}=9.5 \mathrm{kVAr}, \mathrm{QC}=5 \mathrm{kVAr}$ \\
Load 2 & $\mathrm{P}=100 \mathrm{~kW}, \mathrm{QL}=10 \mathrm{kVAr}, \mathrm{QC}=5 \mathrm{kVAr}$ \\
Load 3 & $\mathrm{P}=100-120 \mathrm{~kW}, \mathrm{QL}=11 \mathrm{kVAr}, \mathrm{QC}=5 \mathrm{kVAr}$ \\
Load 4 & $\mathrm{P}=30 \mathrm{~kW}, \mathrm{QL}=10.5 \mathrm{kVAr}, \mathrm{QC}=5 \mathrm{kVAr}$ \\
Load 5 & $\mathrm{P}=30 \mathrm{~kW}, \mathrm{QL}=9 \mathrm{kVAr}, \mathrm{QC}=5 \mathrm{kVAr}$ \\
\hline
\end{tabular}

\subsection{Proposed voltage and frequency controller}

The intended purpose of proposed controller is regulating voltage and frequency between DG and PCC. When the MG is connected to main grid, voltage and frequency is controlled by dominant grid supply at PCC. Whereas, when there is fault on grid side or it is disconnected for maintenance purpose, DG's should look after the voltage and frequency profiles. In that condition, the projected controller will regulate these profiles and maintain rated voltage supply at load side.

The outlined controller for voltage and frequency is shown in Figure 2. Where, measured voltage and reference voltage is converted from three phase a-b-c to synchronously rotating dq0 components by using Park's transformation utilizing Equation (1).

$$
\left[\begin{array}{l}
i_{d} \\
i_{q}
\end{array}\right]=\left[\begin{array}{lll}
\sin \theta & \sin \left(\theta-\frac{2 \pi}{3}\right) & \sin \left(\theta+\frac{2 \pi}{3}\right) \\
\cos \theta & \cos \left(\theta-\frac{2 \pi}{3}\right) & \cos \left(\theta+\frac{2 \pi}{3}\right)
\end{array}\right] *\left[\begin{array}{l}
i_{a} \\
i_{b} \\
i_{c}
\end{array}\right]
$$

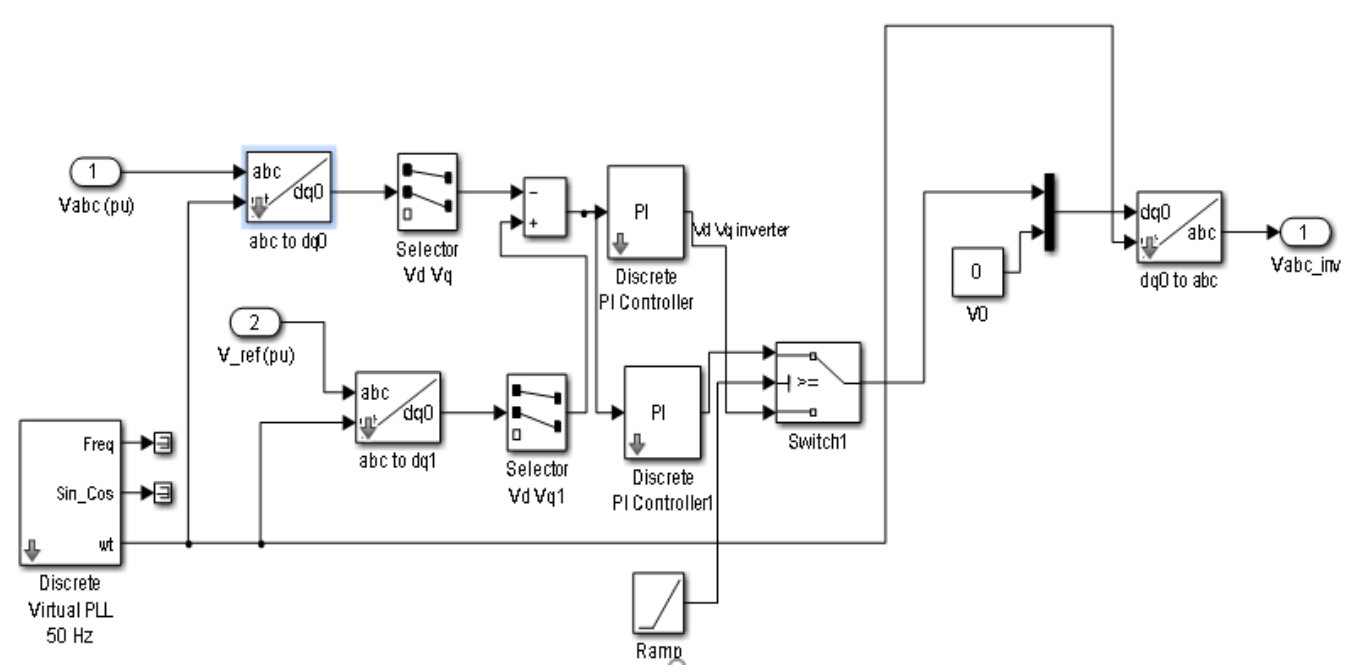

Figure 2. Proposed controller scheme

The output of proposed controller is feed to PWM pulse generator for generation of appropriate pulses for inverter. During grid connected mode, inverters connected with each DG supplying sinusoidal voltage at 1 p.u. At the instance of fault at grid side or disconnection of grid from MG, there will be fluctuation in voltage supply at PCC and this may lead to increase in current and will affect consumer devices [19]. To overcome this effect, the proposed PI controller will process the difference between measured voltage of each DG and PCC and accordingly output its signal to PWM generator. Here zero sequence components are taken into account as the proposed system is three phase three wire system and there is no zero sequence component exists in this system [20]. Configuration of proposed controller with DG unit in block diagram is shown in Figure 3.

For verifying operation of proposed controller, firstly simulation was running normal with connected grid, during this time there was constant voltage and frequency at all buses and PCC. But at $t=0.5 \mathrm{~s}$ grid is disconnected by opening breaker, at this instant voltage and frequency becomes disturbed. Just after disconnection of grid, proposed controller considering the voltage and frequency profile to return to its normal value to avoid any undesirable situation. In the next section, detailed simulation results are displayed and discussed. The effectiveness of the proposed controller will be verified during the variations in the load, which is also discussed. 


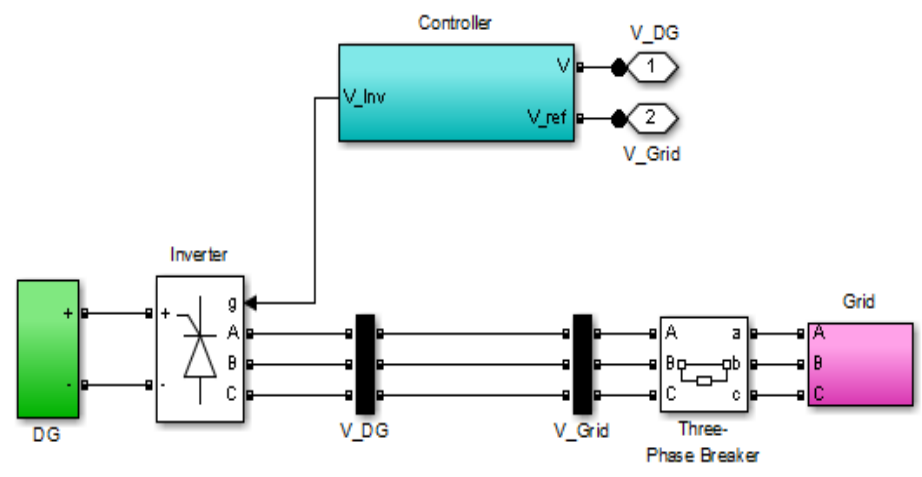

Figure 3. Configuration of Controller with DG

\section{RESULTS AND ANALYSIS}

As mentioned in last section, initially simulation is run with grid connected mode and at $t=0.5 \mathrm{~s}$ operating mode changed to islanding, at that moment voltage and frequency become unbalanced. During islanded mode, MG must take care of frequency and voltage to supply sinusoidal power to consumers. Figure 4 below is portraying voltage measured at terminal of PV array. From the figure, it is shown that after $\mathrm{t}=0.5 \mathrm{~s}$ voltage have fluctuation and transients which makes $D G$ voltage unstable. This variation in voltage will affect the supplied voltage to the consumer. Therefore, proposed intelligent controller will mitigate the effect and DG's will continue to supply rated voltage. Further, at $\mathrm{t}=0.7 \mathrm{~s}$ there is increase in load from 100 $\mathrm{kW}$ to $120 \mathrm{~kW}$ and again the fluctuations at terminal voltage of DG unit, which is again not favourable for the consumer's devices.

As shown in Figure 4, when simulation reaches at $t=0.5 \mathrm{~s}$, the MG transit to islanding mode, and the voltage supplied by DG with PI controller have less fluctuations and its settle down within $0.02 \mathrm{~s}$ as compared to without PI controller which has more fluctuations and settling time is $0.05 \mathrm{~s}$. The same is the case during increase in load, proposed controller with PI controller have better results than witout PI controller. Furthermore, the voltage overshoot during switching phase is also not a desirable condition for some sensitive loads. Here, in this case controller with PI have less overshoot as compared to without PI controller which is 1.62 p.u. in comparison to 1.22 p.u.

For the case of frequency, there also happen variations during transition of MG operation mode and load changing. The output of frequency during this condition is shown in Figure 5 below. From the figure, it is evident that proposed controller with PI controller have achieved better results as compared to without PI controller. The settling time and overshoot of PI controller is also less as compared to other case. The maximium overshoot is 1.0009 p.u. in comparison to 1.0012 p.u. The settling time is $0.11 \mathrm{~s}$ as compared to $0.13 \mathrm{~s}$ in case of without PI controller. The overall performance of proposed controller in comparison to other technique, the total harmonic distortion (THD) of DG current and voltage is also within the specified limits of IEEE-1547-2003 standard for interconnetion of distributed generators with power system.

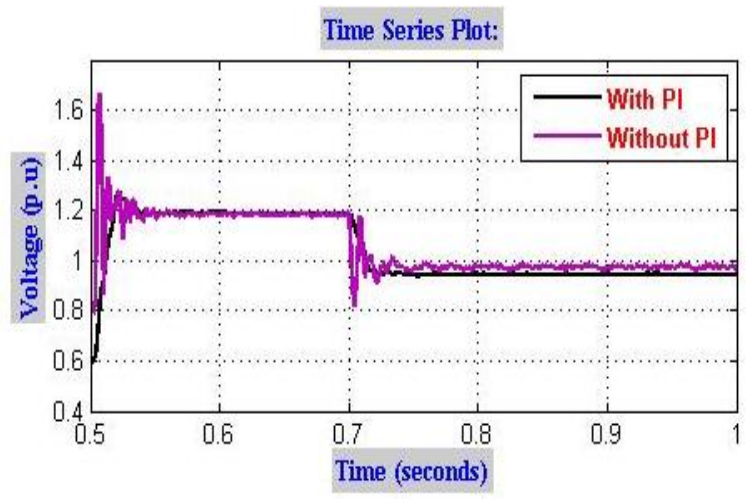

Figure 4. Voltage at terminal of PV array

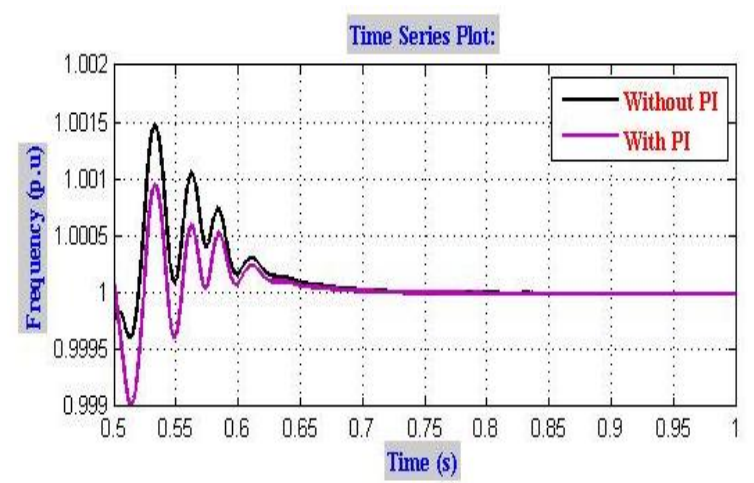

Figure 5. Frequency supplied by PV array 
The dynamic behaviour of voltage and current of PV array during transition phase is given in Figure 6 and Figure 7 respectively. With the proposed controller, DG is supplying almost sinusoidal voltage and current with less THD levels.

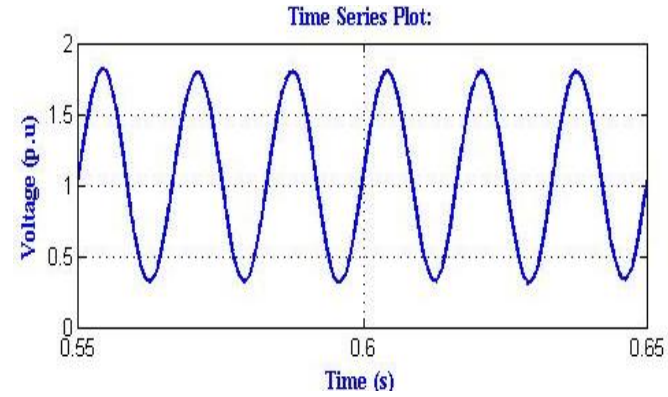

(a)

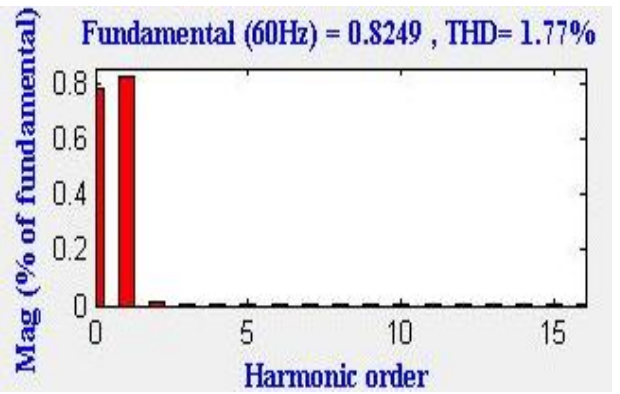

(b)

Figure 6. DG parameters with proposed Controller (a) Voltage, (b) DG voltage THD

As shown in Figure 6(a) and Figure 6(b), the output voltage of DG is pure sinusoidal and stable waveform. Its THD level is also within the IEEE specified limits. Further, the condition of output current of DG and its THD level is given below in Figure 7(a) and Figure 7(b). From the below figure it is evident that the proposed controller is capable to supply approximately pure sinusoidal wavefoem regardless of the modes of operation of microgrid.

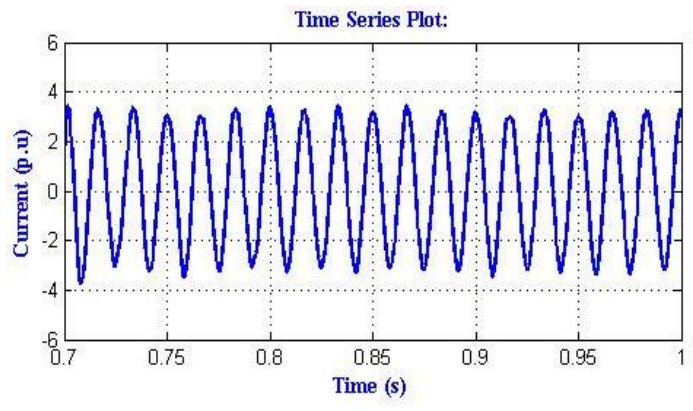

(a)

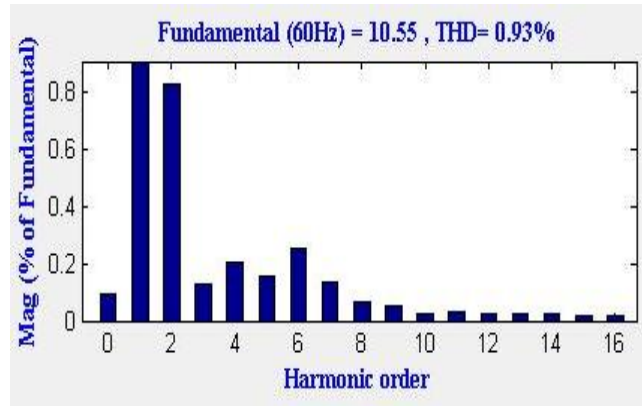

(b)

Figure 7. DG parameters with proposed Controller (a) Current, (b) DG current THD

\section{CONCLUSION}

In this research, voltage and frequency controller has been proposed for regulating voltage and frequency of MG when it comes to islanding mode. The proposed controller utilized conventional PI controller to regulate voltage and frequency. Simulation results have verified the capability of proposed system in regulating profiles. Results also depicts that while regulating voltage, power supplied by DG's is also maintained at their rated value after being disconnected from main grid. To verify the functionality of proposed system, researcher may contemplate different nature of DG's especially renewable sources on the supplied voltage can be considered for future work.

\section{ACKNOWLEDGEMENTS}

The authors would like to acknowledge the facilities provided by Universiti Teknologi Malaysia for the accomplishment of this work and Ministry of Education (MoE) of Malaysia for their financial support under vote number GUP UTM 17H10. Sajid Hussain Qazi is also thankful to Mehran University of Engineering and Technology Shaheed Zulfiqar Ali Bhutto Campus, Khairpur Mir's, Sindh, Pakistan for providing financial assistance under Faculty Development Program (FDP). 


\section{REFERENCES}

[1] M. Shao, et al., "Control strategy of voltage and frequency for islanded microgrid," in 7th International conference on Power Electronics and Motion Control (IPEMC), pp. 2085-2089, 2012.

[2] Z. Jiang and $\mathrm{X}$. Yu, "Active power-Voltage control scheme for islanding operation of inverter-interfaced microgrids," in 2009 IEEE Power \& Energy Society General Meeting, pp. 1-7, 2009.

[3] S. Rahman and H. A. Rahman, "Use of Photovoltaics in Microgrid as Energy Source and Control Method Using MATLAB/SIMULINK," International Journal of Electrical and Computer Engineering, vol. 6, pp. 851, 2016.

[4] L. Zhang, et al., "Study on improvement of micro-grid's power quality based on APF and FESS," in IEEE Innovative Smart Grid Technologies-Asia (ISGT Asia), pp. 1-6, 2012.

[5] S. H. Qazi, et al., "Enhanced Power Quality Controller in an Autonomous Microgrid by PSO Tuned PI Controller," Indian Journal of Science and Technology, vol. 8, 2017.

[6] R. M. Strzelecki, "Power electronics in smart electrical energy networks," Springer Science \& Business Media, 2008.

[7] F. Katiraei and M. R. Iravani, "Power management strategies for a microgrid with multiple distributed generation units," IEEE transactions on power systems, vol. 21, pp. 1821-1831, 2006.

[8] R. Palanisamy, "Parallel connected VSI inverter using multi-carrier based sinusoidal PWM technique," TELKOMNIKA (Telecommunication Computing Electronics and Control), vol. 15, 2017.

[9] S. Chowdhury and P. Crossley, "Microgrids and active distribution networks," The Institution of Engineering and Technology, 2009.

[10] S. H. Qazi, et al., "Current Harmonics Mitigation from Grid Connected Variable Speed Wind Turbine due to Nonlinear Loads using Shunt Active Power Filter," Jurnal Teknologi, vol. 4, pp. 45-53, 2017.

[11] K. Rathi and N. R. Prabha, "Grid Interconnected Photo Voltaic System Using Shunt Active Filter forPower Quality Improvement," International Journal of Power Electronics and Drive Systems (IJPEDS), vol. 9, 2018.

[12] M. A. Pedrasa and T. Spooner, "A survey of techniques used to control microgrid generation and storage during island operation," in Proceedings of the Australasian Universities Power Engineering Conference (AUPEC), pp. 1-6, 2006.

[13] R. Majumder, et al., "Improvement of stability and load sharing in an autonomous microgrid using supplementary droop control loop," IEEE transactions on power systems, vol. 25, pp. 796-808, 2010.

[14] A. J. Lampiao, et al., "Control of an Autonomous Hybrid Microgrid as Energy Source for a Small Rural Village," International Journal of Electrical and Computer Engineering (IJECE), vol. 7, 2017.

[15] Z. Zhao, et al., "Steady-state voltage stability analysis and improvement strategies of microgrid with double fed induction wind generator," in 18th International Conference on Electrical Machines and Systems (ICEMS), pp. 1063-1068, 2015

[16] S. H. Qazi, et al., "Comparison of reference signal extraction methods for active power filter to mitigate load harmonics from wind turbine generator," in IEEE Conference on Energy Conversion (CENCON), pp 463-468 2015.

[17] M. Hadinezhad and M. Gandomkar, "Voltage Control of Microgrid Systems Connected to Power Network System in Fault Condition," vol. 04, pp. 1087-1097, 2013.

[18] S. Vashishtha and K. Rekha, "Space Vector PWM in Three-phase Voltage Source Inverter: A Survey," International Journal of Electrical and Computer Engineering (IJECE), vol. 8, 2017.

[19] S. H. Qazi and M. W. Mustafa, "Review on active filters and its performance with grid connected fixed and variable speed wind turbine generator," Renewable and Sustainable Energy Reviews, vol. 57, pp. 420-438, 2016.

[20] W. Al-Saedi, et al., "Power flow control in grid-connected microgrid operation using Particle Swarm Optimization under variable load conditions," International Journal of Electrical Power \& Energy Systems, vol. 49, pp. 76-85, 2013. 